\title{
Phillip Harris - The end of an era
}

The editor of Spinal Cord retires with effect from this issue of the journal and we would like to pay tribute to his remarkable career in scientific editing. Since the launch of Spinal Cord (then Paraplegia) in 1963, Phillip Harris has worked first as Assistant Editor then as Editor of the journal, which shows an extraordinary commitment to the field of spinal injury research.

The journal was launched by Sir Ludwig Guttmann in 1963 to provide a vehicle for the publication of papers on all apsects of spinal injury. The wide ranging multi system effects of spinal cord injury need a coordinated approach from surgeons, physicians, psychologists, occupational therapists, physiotherapists, social workers and nurses. Paraplegia provided the vital forum for these groups to publish and read the latest research in this challenging area. As the subject developed the journal grew from quarterly to bimonthly and then to nine issues a year from 1990. January 1992 saw the first monthly issue.

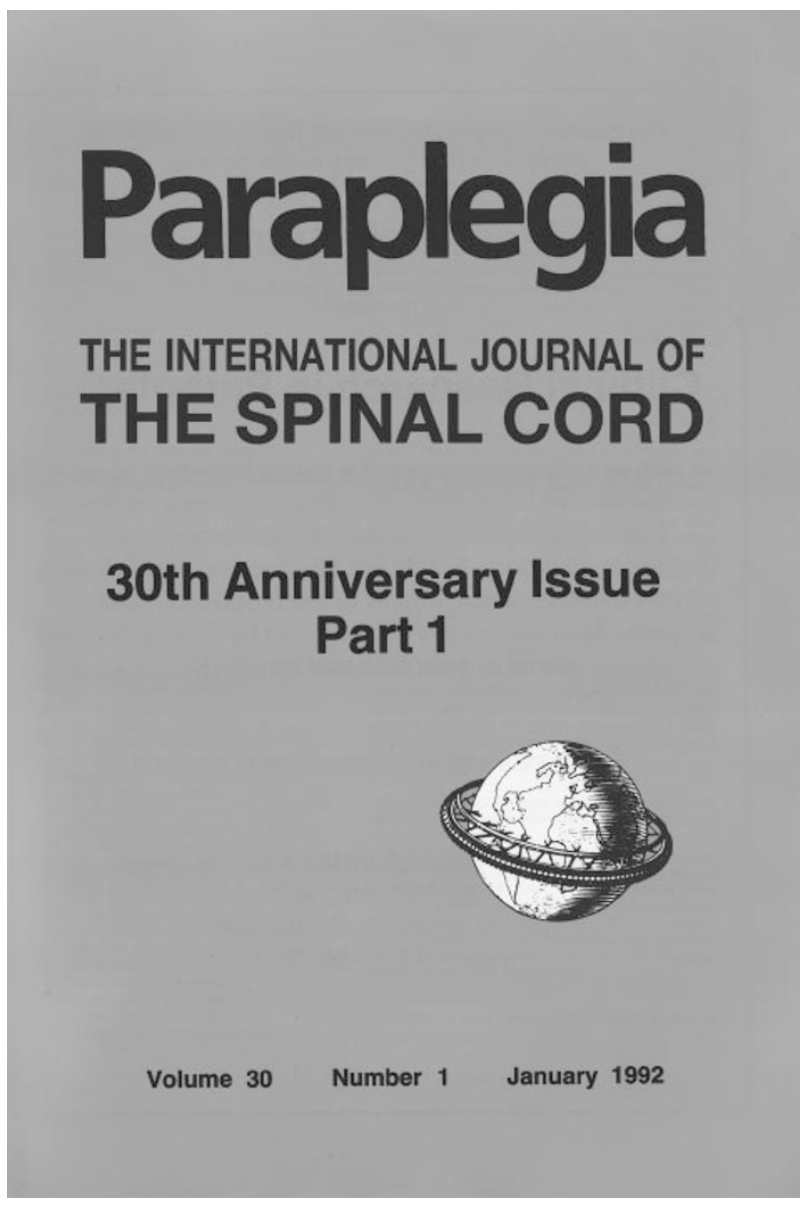

This was also the thirtieth year of publication of the journal and was marked by a special anniversary issue. ${ }^{1}$

Phillip Harris worked as Assistant Editor from the first issue in 1963 and took over as Editor following the sudden death of Sir Ludwig Guttmann in 1980. He brought to the role a very considerable experience in the field of neurosurgery. $\mathrm{He}$ is well known and respected worldwide and has helped to develop spinal injury centres in many countries. He is a Fellow of the Royal Society of Edinburgh and a founder member and past Chairman of a number of national and international learned societies, such as the International Medical Society of Paraplegia, the Scottish Association of Neurological Sciences and the British Cervical Spinal Society. He is also Director of Spinal Injury Studies of the World Federation of Neurosurgical Societies.

Stockon Press first started discussions with The International Medical Society of Paraplegia (IMSOP) in December 1985 with a view to publishing the journal. However, a new publishing contract was not signed until May 1991. The first issue published by Stockton Press was therefore the Anniversary issue marking 30 years of publication and Phillip Harris' 10 years as Editor. The journal has continued to develop in the last 7 years, with a new, larger, format and a bright new cover design in 1995 and then a significant change of title to Spinal Cord in April 1996 to recognise the changes taking place in this subject area.

The journal has continued, under the guidance and leadership of Phillip Harris, to publish high quality research papers from around the world. The effects of this can be seen in the growth in subscription sales over the last five years. During a period when most mature journals have seen their institutional subscription numbers dropping by as much as $10-15 \%$ per year, Paraplegia and then Spinal Cord has seen its readership grow by $3 \%$ since 1992 . In addition to this, IMSOP has also seen a significant increase in its membership.

An editor must have a clear vision for the journal and act as a firm but fair moderator of scientific debate. No one can doubt that Phillip Harris has guided the journal well and has worked hard to make sure that it does not stand still. In changing the title to Spinal Cord, Phillip Harris campaigned hard to convince his colleagues that the name 'Paraplegia' was rather outdated and did not reflect the current interests of those working in the field.

It is clear to those who work with Phillip Harris that his motivation is always to widen knowledge and understanding of spinal injuries and their treatment. 


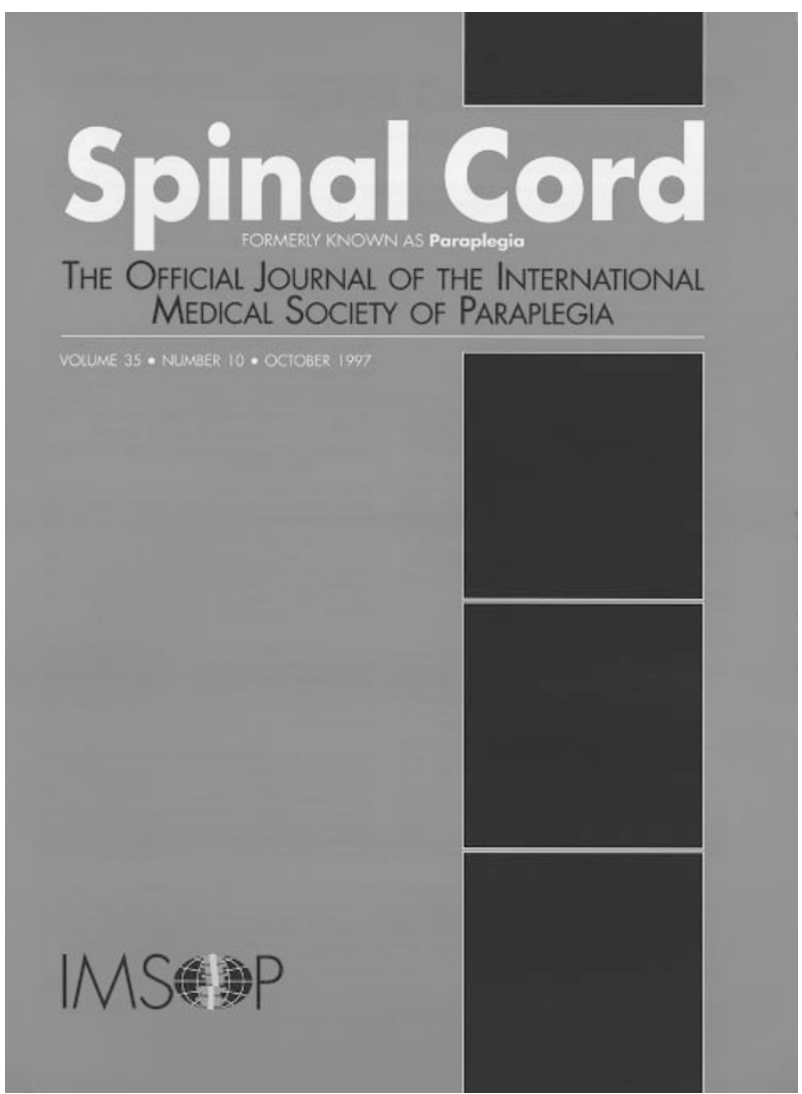

He is constantly pushing fellow editors, editorial board members, IMSOP and his publishers to improve the journal and through this the treatment of the patients who live with terrible injuries. He is always looking to the next development, the next improvement and he has been particularly keen to see the journals' papers being made available over the Internet. We are delighted to be able to announce in this Phillip's last issue that online publishing will commence in January 1998.

In planning the new Stockton Online service, our goal has been to increase the readership of our journals, an aim enthusiastically supported by Phillip Harris. The contents pages of the Stockton journals have been available for some time on a web site (url: http://www.stockton-press.co.uk) and are e-mailed free of charge to anyone who wishes to receive them. The new service will allow users to view and search the contents pages and abstracts of all issues from the beginning of 1997. Full text will be available in PDF (portable document format) to allow good quality printing of papers and in html (hyper-text mark-up language) to allow comprehensive searching across all issues of Spinal Cord and other journals published by Stockton Press.

In developing an online publishing system, it has been important to balance the need to protect the content of the journal from being used by unauthorised users and promoting the readership of papers as widely as possible. Subscribers to Spinal Cord will therefore be able to choose whether to subscribe to the print version of the journal or the electronic version for the same price. If subscribers wish to take both versions then the charge will be just $10 \%$ more on the subscription price. Institutions will be able to opt for a site licence agreement which allows the users of the library unlimited access to the journal, thus enhancing the value of the journal. No longer will readers find that the very issue they wish to read is being used by a colleague. It will be available to all at the desktop.

Stockton Press recognise that scientists wish to search across a broad literature from many publishers and it is therefore our intention to make links from key bibliographic services to our online content. These developments will take place over the next year and will greatly enhance the service we can offer to our customers. Online publishing offers many opportunities to improve the flow of information to researchers and offers an exciting future for journal publishing.

It is always good to work with an editor who has an enthusiastic approach to their journal. The job of editor is demanding and often brings the editor into conflict with his peers. This has never daunted Phillip Harris and he has worked for 34 years to ensure the success of this journal, a magnificent achievement. $\mathrm{He}$ has shown dedication, determination and leadership and the journal is undoubtedly the better for it. He has always ensured that he gets the best from his publishers through persistence and humour and it has been a privilege to work with him. All of the staff at Stockon Press would like to wish him a happy and well earned retirement from the editorship of Spinal Cord.

Jayne Marks Publishing Director

\section{Reference}

1. Spinal Cord 1992; 30: 1-76. 